\title{
Understanding and Designing Cool Technologies for Teenagers
}

\author{
Janet C Read \\ ChiCI \\ Russell Beale \\ School of Computer Science \\ University of Central Lancashire The University of Birmingham \\ Preston, PR1 2HE UK \\ jcread@uclan.ac.uk \\ Edgbaston, B15 2TT, UK \\ r.beale@cs.bham.ac.uk \\ Daniel Fitton \\ ChiCI \\ Yukang Guo \\ University of Central Lancashire Swansea University \\ Preston, PR1 2HE UK \\ dbfitton@uclan.ac.uk \\ Benjamin R Cowan \\ School of Computer Science \\ The University of Birmingham \\ Edgbaston, B15 2TT, UK \\ b.r.cowan@cs.bham.ac.uk \\ Swansea, SA1 1XW, UK \\ y.guo@swansea.ac.uk \\ Matthew Horton \\ ChiCI \\ University of Central Lancashire \\ Preston, PR1 2HE UK \\ mplhorton@uclan.ac.uk
}

\begin{abstract}
This paper describes how initial principles for the designs of an interactive application were informed from a study of 'coolness' with two different ages of teenagers. The study used drawings to examine how teenagers might design their environments and these were then analysed by the research team based on a set of characteristics of cool that were drawn from the literature. Results from the teenagers' drawings demonstrate some change in emphasis between the younger and older age groups and between the genders. A design space around innovation and rebellion is implicated in the findings.
\end{abstract}

\section{Keywords}

Design, Teenagers, Child Computer Interaction, Cool Design

\section{ACM Classification Keywords}

H5.m. Information interfaces and presentation (e.g., $\mathrm{HCI}$ ): Miscellaneous.

\section{General Terms}

Design, Theory 


\section{Introduction}

The context of this work is a three-year project aimed at designing and developing technologies that change the way the teenagers think about, and use, energy. The intention is to persuade teenagers to adopt an ecofriendly lifestyle and help them to build up some positive habitual behaviour on energy saving which will last through their adulthood. Central to this project is an emphasis on exploring how best to design interactive technology, interactivity and interfaces that appeal to a large section of the teenage population. These technologies are expected to include, but are not limited to, mobile devices, situated sensors, web services, e.g. social network, and augmented reality. With a history of designing with children and teenagers, as opposed to simply designing for children and teenagers, the project team made an early commitment to work directly with the eventual end users of the technologies in order to better understand teenage motivations and ideals, to gather ideas and opinions from teenagers and to ignite teenage enthusiasm and acceptance. This paper describes an early stage in this process by outlining how the team explored, discovered and understood some of the elements of design for teenagers in work that investigated what could be learnt from 'cool' as it is situated in teenage lives.

\section{Designing for Teenagers}

There is only limited literature on designing for and with teenagers. There are several reasons for this: one is that the work on understanding design for any nonadults is still quite new and so there is some catching up to be done; a second reason is that access to teenagers is sometimes difficult as their schoo structures are quite rigid and so researchers can be 'put off' this group of users; a third is that the worlds that teenagers inhabit are quite secretive and are difficult to get into and so it can be hard to make sense of these spaces. The project team doing this work has previously carried out design studies with teenagers taking a model that we previously developed for use with younger children and applying this, with adaptations. In the original work children are given paper and other artifacts and then design products or parts of products which are later interpreted by adults and used as inspiration for interface and interaction design [6]. The current work varies slightly from that approach in that the intention, in doing the design sessions, was not to explore a specific technology or product but rather to examine what it is about products and technologies that makes them 'cool' and therefore makes them into 'must have' items. This exploration needed to result in an understanding of how to embed 'coolness' into technology design.

\section{Theorising about Cool Design}

There is much written about what it is to 'be cool' (e.g. $[8],[9])$ and the impact of 'cool' on the way teenagers appropriate technology [4] [5]. Within 'cool'

communities such as a teenager's peer group, it is assumed that people can identify that certain things and certain people are 'cool'. In understanding 'cool' from the standpoint of onlooker it is still believed that there can be a general understanding of cool that is shared amongst people - almost like the way we share an understanding of 'nice'. Whilst people may claim to easily identify what is and is not cool an agreed

definition of the concept is elusive in the literature [1]. Cool has been described in terms of adjectives by many different commentators - some take a view of cool as being very much about consuming, others focus on cool 
as it applies to behaviours. Theories of the causes and motivations for cool also highlight the importance of the earning of social capital within cool subgroups through cultural subgroup emulation [2] and autonomy from mainstream society [3].

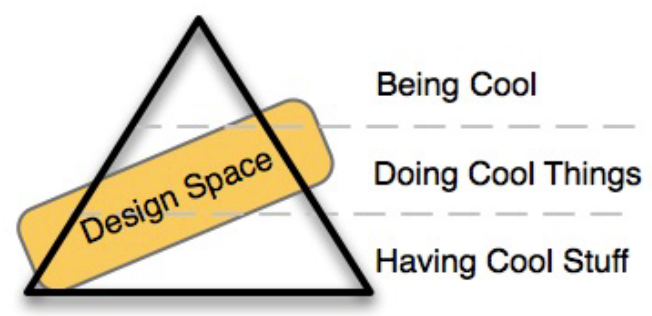

Figure 1 - The Hierarchy of Cool

Our initial theory of cool is that it is different things in diminishing proportions within a hierarchy. At the top of this hierarchy (as shown in Fig 1), there is the being of cool, next there is the behaviour of cool (doing cool), and lastly, most common, there is the having of cool items. In this hierarchy, the coolness at the top, is believed to be the most difficult to achieve. This diagram on its own cannot determine what cool is; for this the literature was examined and the work of several authors was distilled to create a table of Essential Categories of Cool (Table 1). We would accept that there are variants of this table, and potentially other categories: however, one of the points of this initial study was to see if these initial categories could be used as the basis to provide insight into coolness, and hence shape further research.

From the hierarchy and the characteristics, our initial hypothesis in designing for 'cool' was that it may be possible to design cool products, but what is more enchanting is the possibility to design for cool, that is to design products that will allow cool behaviours as promised in the second level of our hierarchy.

Table 1 - Essential Categories for Cool

\begin{tabular}{|l|l|}
\hline CODE & Explanation and References \\
\hline REB & $\begin{array}{l}\text { Rebellious and / or illicit (probably has some } \\
\text { socially or morally unacceptable line to it) [9]. }\end{array}$ \\
\hline AS & $\begin{array}{l}\text { Anti social (encourages anti social behaviours - } \\
\text { maybe avoiding the need to mix with others or } \\
\text { encouraging anti social behaviours like bullying } \\
\text { and violence) [9] }\end{array}$ \\
\hline RET & Retro (clearly from a previous era) [7]. \\
\hline AUTH & $\begin{array}{l}\text { Authentic - the real thing (more about items } \\
\text { that are 'the must have' brands - and maybe } \\
\text { are 'hip' or trendy at the moment) [10], [7]. }\end{array}$ \\
\hline RICH & $\begin{array}{l}\text { Many desire - affordability issues - big money } \\
\text { (probably less about brands and more about } \\
\text { features - where having this item would mainly } \\
\text { signify you have a lot of money to spend) [8] } \\
\text { (in reference to Aston Martin cars). }\end{array}$ \\
\hline INN & $\begin{array}{l}\text { Innovative - original (something that is really a } \\
\text { bit of a surprise - where - on encountering this } \\
\text { thing - people would be impressed by it for its } \\
\text { unusualness rather than for any of the other } \\
\text { items above) [8]. }\end{array}$ \\
\hline
\end{tabular}

Our understanding is that while certain products are inherently cool, for example, the Harley Davidson motorcycle, some products are only cool when placed in a certain context or situation, and other products need more than context to be cool - they have to be appropriated by a 'cool' person. This perspective is often adopted by marketing and advertising agencies, whose commercial remit is often to make the thing that they are selling a 'must-have' item, and they often achieve this through celebrity takeup either directly via endorsement or indirectly though sponsorship. This association of the item with an aspirational person or lifestyle is a strong push in the creation of cool 
products, but also highlights the difficulties of pinning cool down: cool can be something used by a famous person, perceived as the pinnacle of societal aspiration, or it can be the complete opposite - rebellious or antisocial. However, this view of cool is not possible for us to design for, being a commercial transaction, but the first two certainly seem to offer possibilities for interaction designers.

\section{Study}

To examine our thinking and prompt discussion, a study was designed to further inform our understanding of 'cool'. The study began with a period of working with two different ages of pupils in a UK school (Year 7, aged 11-12, and Year 10, aged 14-15 and chosen as being the lower bounds of the two age groups that we are primarily concerned with) and then continued through an analysis process that brought in a diverse set of researchers to categorise the children's work. The numbers in each section (boys, girls, ages) are shown in parentheses in the first column in table 2.

The School Activity

The activity was termed 'Design your life' and was presented during a standard class lesson (55 minutes) with a full class of children. Prior to the session, the research team had prepared large sheets of paper with room plans on them. Students worked in same sex pairs determined by the class teacher (each pair designing a single room) using coloured pens and crayons. In a five-minute introduction at the beginning, they were instructed to create, in the context of their bedrooms, the 'life they would like to have' but were specifically told to not go into the realms of fantasy; they were then left to carry on with their designs.

\section{Analysis of Findings}

Analysis of the findings was carried out in three stages. Initially, one researcher systematically went through each picture and listed every item that had been placed in it. These items ranged from being very ordinary things, like beds, to really crazy things like helicopter pads and room sized hamster runs. For the ordinary things, aligning with our view of making things cool, any special features in regard to design, manufacturer, specifications etc. were noted - thus if the bed had pink silk sheets this detail was included on the summary sheet. In stage two of the analysis, four different researchers each categorized the individual rooms using the descriptions and codes shown in Table 1. Each was told specifically to only choose a single category for each item (or none), but some gave multiple categories. The four researchers did not see one another's categories. In stage three of the analysis the four sets of results from the categorization process were investigated and aggregated into a single

category for each item in the picture. Where there was a clear 'leader' this was chosen; where there was not a clear leader the item was left as uncertain and no code given. Where none of the four evaluators, or only a small subset of the evaluators, had considered an item to be cool, the item was described as not cool. These two categories were interesting (uncertain and not cool) but are not discussed in this paper as they are beyond the scope of this specific study.

\section{Results}

All the teenagers found creating and populating their rooms straightforward and they worked enthusiastically and with humour and focus. An example from one group is shown in Figure 2. Data was analysed in four groups according to gender and age. Table 2 below 
shows the average number (averaged across the number of groups of teenagers) of cool items associated with each of the cool categories.

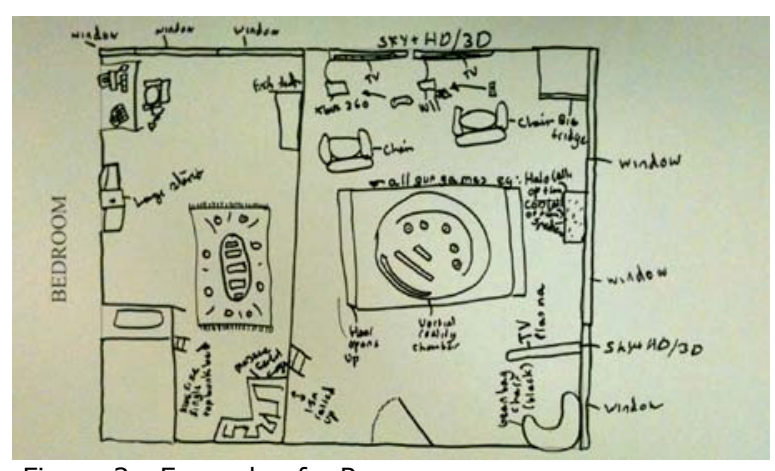

Figure 2 - Example of a Room

Table 2 - Averages of Each Classification

\begin{tabular}{|l|l|l|l|l|l|l|}
\cline { 2 - 7 } \multicolumn{1}{c|}{} & \multicolumn{6}{c|}{ Cool Classifications } \\
\hline By class & REB & AS & RET & AUTH & RICH & INN \\
\hline YR7GIRLS (10) & 0.1 & 0.6 & 0.2 & 0.9 & 1.5 & 3.2 \\
\hline YR7BOYS (5) & 0.0 & 0.6 & 0.0 & 0.4 & 4.2 & 3.8 \\
\hline YR10BOYS (5) & 1.2 & 0.5 & 0.3 & 1.0 & 2.5 & 0.7 \\
\hline YR10GIRLS (4) & 0.0 & 0.5 & 0.8 & 0.8 & 3.8 & 1.3 \\
\hline By gender & & & & & & \\
\hline BOYS (11) & 0.6 & 0.5 & 0.2 & 0.7 & 3.3 & 2.1 \\
\hline GIRLS (14) & 0.1 & 0.6 & 0.4 & 0.9 & 2.1 & 2.6 \\
\hline By age & & & & & & \\
\hline YR7 (15) & 0.1 & 0.6 & 0.1 & 0.7 & 2.4 & 3.4 \\
\hline YR10 (10) & 0.7 & 0.5 & 0.5 & 0.9 & 3.0 & 0.9 \\
\hline Combined & & & & & & \\
\hline ALL (25) & 0.3 & 0.6 & 0.3 & 0.9 & 2.6 & 2.4 \\
\hline
\end{tabular}

When looking at the differences across the two age groups, the key findings are that the year $7 \mathrm{~s}$ were much more likely to have innovative items (3.4 as opposed to 0.9 ) and the year 10 s were more likely to have rebellious items and behaviours ( 0.7 versus 0.1 ) and five times more likely to be retro ( 0.5 versus 0.1 ). Looking at gender differences, boys were more likely to be more rebellious ( 0.6 versus 0.1$)$ and also preferred rich items ( 3.3 versus 2.1). Table 3 shows some of the ideas that were found in the drawings.

Table 3 - Examples of Teen Cool Items in Categories

\begin{tabular}{|l|l|}
\hline CODE & Examples \\
\hline REB & Love room and drinks (alcoholic) cabinets \\
\hline AS & Door locking and fridges in rooms \\
\hline RET & Old fashioned phones and disco balls \\
\hline AUTH & Apple products and Xboxes \\
\hline RICH & 100 inch 3D surround sound TVs \\
\hline INN & $\begin{array}{l}\text { Semi circular bed with surrounded fish } \\
\text { tank illuminated by purple LEDs }\end{array}$ \\
\hline
\end{tabular}

\section{Discussion of Findings - Cool Design}

Referring back to the Hierarchy of Cool and examining the items from the teenage bedrooms, two key findings are reported. The first is the association between the categories that were used and the hierarchy. It may be that the three categories RET (retro), AUTH (authentic) and $\mathrm{RICH}$ (high value) are primarily associated with items or products and have little scope in terms of behaviours. It is difficult to imagine how a teenager could make a non-authentic product into an authentic one. On the other hand REB, (rebellious) AS (antisocial) and INN (innovative) may be easier to 'create' from ordinary things. Our study also showed differences in cool across the ages and genders. Whilst these need to be further explored, it appears that innovation, rebellion, value and retroness are all values that have different foci. Innovation and rebellion may turn out to be key aspects of cool. 
When we started this study, many of the team were unconvinced that we could find any approach to actively measure cool. However, there is sufficient evidence from this research that it is possible, although there is a lot to be done to make this either inform design, assist in evaluation, or lead to innovation. The strongest result we found is this clear age and gender difference between perceptions of cool. There are issues and problems even in this area, however: it could be that the differences identified are more about imagination and expression than about intrinsic coolness; for example, there is a significant difference between envisaging things that you'd like in your ideal world, putting in things that you know from peer groups norms that are considered cool, and seeing something new for the first time and thinking that that is, intrinsically, cool.

Further work will focus on having the teenagers discuss and examine cool in facilitated sessions and will examine the extent to which the previous experience and knowledge of the research team affects the understanding of cool as gathered from the drawings.

\section{References}

Agosto, D.E. and J. Abbas. High school seniors' social network and other ICT use preferences and concerns. In Proc of ASIST '10. ASIS, Silver Springs, MD, 2010.
[2] Arteaga, S.M., et al. Mobile system to motivate teenagers' physical activity. In Proc of IDC 2010. ACM Press, Barcelona, 2010.

[3] Arteaga, S.M., M. Kudeki, and A. Woodworth, Combating obesity trends in teenagers through persuasive mobile technology. SIACCESS, 94, pages. $17-25,2009$.

[4] Ito, M., "Education vs. Entertainment: A Cultural History of Children's Software." The Ecology of Games: Connecting Youth,Games, and Learning. Edited by Katie Salen. The John D. and Catherine T. MacArthur Foundation Series on Digital Media and Learning.Cambridge, MA: The MIT Press, 2008.

[5] Ito, M., et al. Hanging Out, Messing Around, and Geeking Out: Kids Living and Learning with New Media (1st ed.). The MIT Press. 2009.

[6] Mazzone, E., J.C. Read, and R. Beale. Design with and for disaffected teenagers In Proc of Nordichi 2008. ACM Press, Lund, Sweden 2008.

[7] Nancarrow, C., Nancarrow, P., and Page, J. An analysis of the concept of cool and its marketing implications. Journal of Consumer Research 1, 4, 311-322. 2002.

[8] O'Donnell, K.A. and D.L. Wardlow, A theory of the origins of coolness, Advances in Consumer Research, 27, pages. $13-18,2000$.

[9] Pountain, D., and Robins, D. Cool rules, anatomy of an attitude. New Formations 39: 7-14. 2000.

[10] Southgate, N. Coolhunting, account planning and the ancient cool of Aristotle. Marketing Intelligence \& Planning 21(7): 453-461. 2003. 